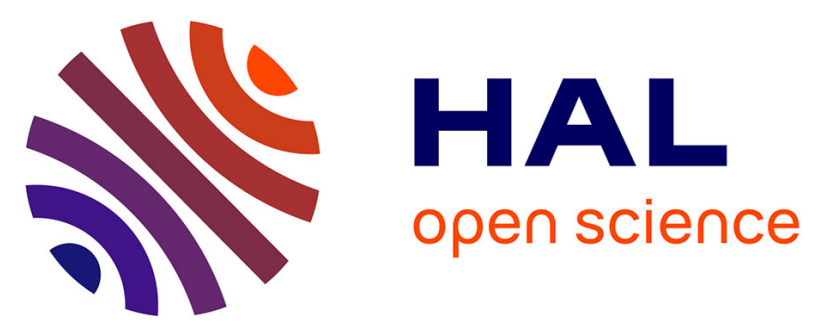

\title{
Management of Reconfigurable Production Networks in Order-Based Production
}

\author{
Johannes Be Isa, Helge Epha, Stefan Braunreuther, Gunther Reinhart
}

\section{To cite this version:}

Johannes Be Isa, Helge Epha, Stefan Braunreuther, Gunther Reinhart. Management of Reconfigurable Production Networks in Order-Based Production. IFIP International Conference on Advances in Production Management Systems (APMS), Aug 2018, Seoul, South Korea. pp.490-497, 10.1007/9783-319-99707-0_61 . hal-02177857

\section{HAL Id: hal-02177857 \\ https://hal.inria.fr/hal-02177857}

Submitted on 9 Jul 2019

HAL is a multi-disciplinary open access archive for the deposit and dissemination of scientific research documents, whether they are published or not. The documents may come from teaching and research institutions in France or abroad, or from public or private research centers.
L'archive ouverte pluridisciplinaire HAL, est destinée au dépôt et à la diffusion de documents scientifiques de niveau recherche, publiés ou non, émanant des établissements d'enseignement et de recherche français ou étrangers, des laboratoires publics ou privés. 


\title{
Management of Reconfigurable Production Networks in Order-based Production
}

\author{
Johannes be Isa ${ }^{1}$, Helge Epha ${ }^{2}$, Stefan Braunreuther ${ }^{3}$ and Gunther Reinhart ${ }^{4}$ \\ ${ }^{1}$ Fraunhofer IGCV, Provinostr. 52, 86153 Augsburg, Germany \\ ${ }^{2}$ Technical University of Berlin, Straße des 17. Juni 135. 17, 10623 Berlin, Germany \\ ${ }^{3}$ University of Applied Sciences Augsburg, An der Hochschule 1, 86161 Augsburg, Germany \\ ${ }^{4}$ Technical University of Munich, Bolzmannstraße 15, 58748 Garching, Germany \\ johannes.beisa@igcv.fraunhofer.de
}

\begin{abstract}
High market volatility as well as increasing global competition in manufacturing lead to a growing demand for flexible and agile production networks. Advanced production systems in turn conduct high capital expenditure along with high investment risks. However, the latest developments of information and communication technology in production environments carry promising optimization opportunities.

The approach of this paper is to apply reconfigurable production networks for scalable capacity and low capital expenditure by adapting "Production planning as a service". Therefore, a genetic algorithm was applied to solve a complex optimization problem. At the end of this work, a prototypical application of the discussed subject is shown on a world-leading household appliance manufacturer.
\end{abstract}

Keywords: Production planning, reconfigurable production networks, masscustomization.

\section{Introduction and motivation}

The current global market situation is characterized by shorter delivery times, higher timeliness as well as high demand volatility [1]. Further saturated markets lead to a trend of customer individualized products in the consumer business sector [2]. In addition, the industry business sector shows a significant trend to higher individualization based on various technical requirements. These trends lead to an increasing number of product variants [2]. High number of variants in turn lead to large inventories in the make-to-stock (MTS) production approach. The MTS approach is very promising and ensures very fast delivery times for the mass production of standardized products. However, this mode of operation bears the risk of overproduction and unsold products in the stock [3].

To tackle this major challenge, manufacturing companies combine the MTS with the make-to-order (MTO) production approach. The combination of the MTS and MTO approaches have been discussed since the mid-1990s [3, 4]. The fact that production forecasts are still very poor is traced back to unforeseeable market shifts and shorter product lifecycles. This expresses the need for fast adaptable production networks to ramp up production capacity in very short timeframes [5]. 
The latest innovations in information technology can be seen as enablers of fast and reliable communication between production sites [2]. This paper discusses an approach to order optimization based on the idea of a Production-as-a-Service concept.

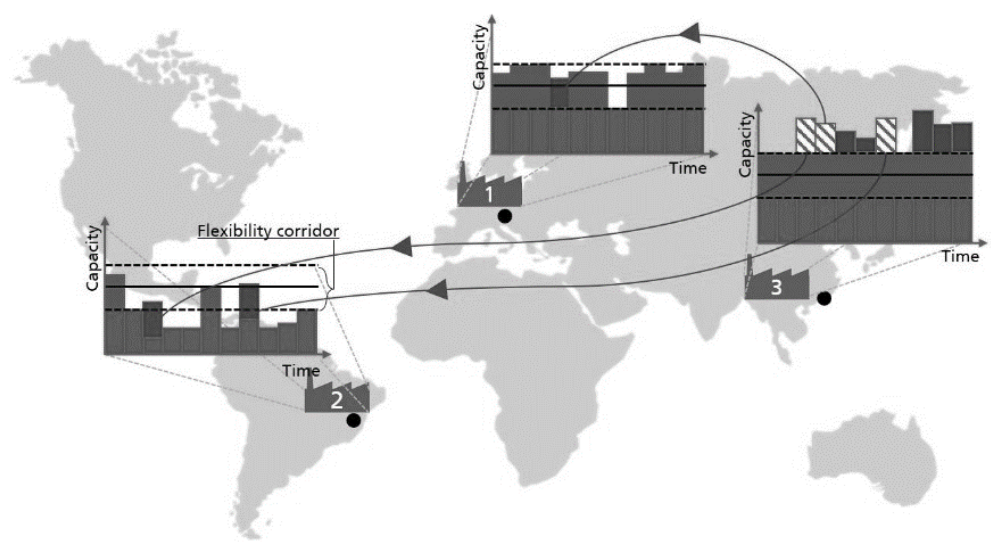

Fig. 1. Model of a simple global production network, characterized by various supply and demand of capacities [6].

Fig. 1 shows a model of a simple global production network. Very typical utilization rates are given; some manufacturing sites have too many free capacities, e.g., factory 2 in the figure, others run an excessive workload, e.g., factory 3. Both of these scenarios are far from an optimal operating strategy [6]. To reach a better solution, a short and mid-term exchange of production orders should be considered. Therefore, reconfigurable production systems are promising. The evaluation of the optimal network reconfiguration will be automatically fulfilled by an applied genetic algorithm.

\section{$2 \quad$ State of the art}

The fundamentals of reconfigurable production systems and production networks in a scalable context are further discussed for a greater understanding of the following reconfiguration aspects in the next chapters.

\subsection{Reconfigurable production systems}

The idea of reconfigurable manufacturing systems (RMS) for quick reactions to market changes started with Koren et al. in the late 1990s [7]. At that time, the majority of applied operation concepts were based on product-specific machining plants and dedicated manufacturing lines (DML). Today, many manufacturing companies still use these concepts; however, some enterprises have decided to install and run flexible manufacturing systems (FMS) [3]. 
Initially, dedicated manufacturing lines are developed for specific products on a mass production scale [5]. The general system as well as the machine structure of the DML concepts are planned and fixed before the start of production. Consequently, DMLs are characterized by fixed capacity limits and lacking responsiveness due to changing conditions [7]. In very stable markets with high batch sizes, it is possible to run such a production system in a cost-efficient way. Fast-changing market circumstances cannot be handled with DML concepts as briefly suggested in Fig. 1.

The flexible manufacturing systems were developed to remedy the disadvantages of the lacking ability to change the machine structure and the missing flexibility of the DML concept. The FMS allows adjustments within a predefined flexibility corridor (see Fig. 1). In contrast to the DML, a corridor is given and not a fixed specific number. This allows you to run the production system in a profitable corridor. Modifications, which go beyond the predefined flexibility corridor, go along with high time and cost efforts. Reconfigurable production systems may comprise several systems, e.g., processing machines, assembly systems and transportation systems. That implies the advantages of dynamic and adjustable systems in terms of capacity, functionality, technology and structure within a cost-effective manner $[7,8,9,10]$.

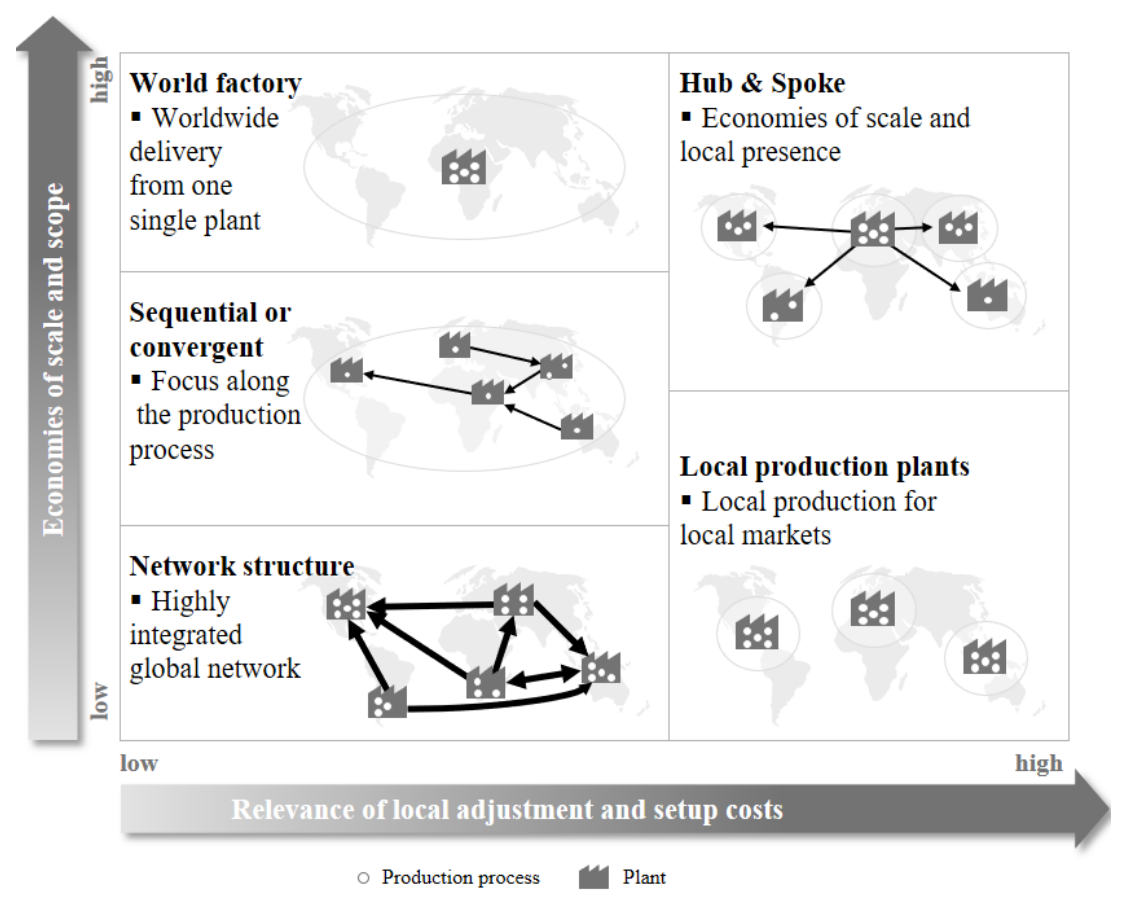

Fig. 2. Different phenotypes of production networks [8]. 


\subsection{Production networks}

The research field of production networks is quite broad and covers various subject areas, e.g., social, economic, environmental and technical aspects. Many questions concerning the strategic set up of those production networks have been discussed in research [3]. The operation and adaptability of those complex production networks are seldom discussed [6]. Hence, there are various descriptions of the term production network. The following definition of Röhrs is technical but generally valid:

A production network can be seen as a network where nodes adopt subtasks of a production process and maintain service exchange relations based on material and information flow [11].

In Fig. 2, a very common distinction between production networks in phenotypes can be found. These phenotypes were described by Abele [8]. Further, the figure shows, on the one hand, the importance of the economies of scale and scope and, on the other hand, the importance of local features and transactional costs.

So far, the short and mid-term move from one phenotype to another has not been investigated in-depth [10]. In the following, this idea will be briefly disscused.

\section{$3 \quad$ Reconfigurable production networks}

Reconfigurable production networks are a promising concept to solve the current and future challenges in production. They consist of highly flexible factories with reconfigurable manufacturing and assembly systems, and they offer the ability of network reconfiguration. The modularity of RMS allows a reconfiguration of capacity, functionality and technology within minutes or hours according to market demands and required products [10]. Due to the increased usability and mobility of the individual elements, reconfigurable production networks enable an agile production in a volatile and competitive environment. Moreover, they increase the possibility of distributing the product portfolio across locations.

The increased technical capabilities of reconfigurable production networks prescribe new requirements for production planning. Westkämper \& Zahn recommended a fundamental change from resource-based to capability-based production planning [12]. Thereby, the degrees of freedom in detailed planning can be increased while the planning accuracy is constant. Automated production planning is feasible based on processing, resource, order and activity models. A core element is a comparison of the processing steps to be manufactured and the available capabilities in the production network. The following concepts applied different algorithms - mainly linear programming, genetic algorithms and game theories - to solve the optimization problem of production planning:

Hees developed a method for the mid-term production planning of RMS based on mixed-integer linear programming (MILP) [10]. The concept aims to align capacity supply and demand. The order allocation within a RMS defines a combinatorial auction designed by Suginouchi [13]. Bensmaine et al. configured a non-dominated sorting genetic algorithm II (NGSA-II) to identify a suitable machine configuration for 
a defined set of orders [14]. The majority of the described concepts focus on the selection of the optimal configuration of the network, RMS and order allocation.

Supply and demand for each period are known and form the basis for the optimization process, which mainly targets minimal production costs.

However, all concepts are limited by the subtasks of production planning and exhibit the following essential weak points: Execution of resource-based instead of capabilitybased production planning; consideration of limited hierarchy levels of a production network and limited dimensions of changeability (product, operation, capacity). What is not taking into account were factory-specific resource differences and logistic expenditures.

A new holistic approach is required to fulfill the requirements of production planning in reconfigurable production systems.

\section{Approach of production planning to reconfigurable production systems}

A concept for capability-based production planning in reconfigurable production systems will be developed. The core element is a genetic algorithm (GA) to solve the problem of optimal order allocation [15].

The requirements of the developed concept are as follows: Orders with a high variety of products and demand have to be allocated to the resources of an established reconfigurable production network. Thereby, on the one hand, production costs have to be minimized and delivery dates fulfilled, and, on the other hand, the three dimensions of changeability for all hierarchy levels of the production network have to be considered.

The selected approach combines the expedient elements of the concepts described in chapter 3 with new elements to fulfill the requirements. It follows the overall approach of capability-based production planning. The basic design comprises the three function modules: order consolidation, capability availableness and order allocation.

The resource model represents the capabilities and characteristics of all resources in the production network (see Fig. 3). Various modules Mm are combined into resource configurations $\mathrm{RCr}$ and provide the specific capabilities for each work station. The supply of capacity for each $\mathrm{RCr}$ is derived from the capacity profiles of the required modules. Consequently, each $R C r$ owns various technology vectors $T V R r, j$. A

configuration matrix stores technical and planning configurations for all $\mathrm{RCr}$ in the production network. The order model represents the entire manufacturing process and the capability demand for each processing step. Analogous to the resource model, technology vectors $T V D d, i$ represent the capability demand. Moreover, quantity, delivery date and location are stored information in the order model. The system model defines production network, factory, RMS and module as the five hierarchy levels of a reconfigurable production network. The numerous variations of the manufacturing process for a product are compiled in a process variations graph. The first function module, order consolidation, initiates the planning process by merging all orders with the same 
product, delivery date and location to a production order, except orders with a starting time within the frozen zone or high urgency.
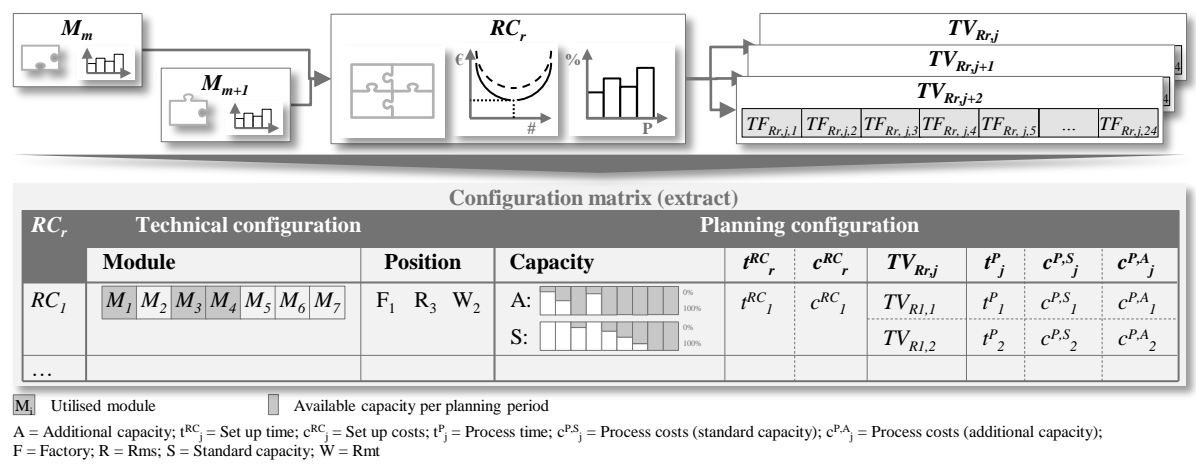

Fig. 3. Configuration matrix representing supply of capabilities and capacity.

The concept of demand-capability comparison based on technology vectors is the core element of the module capability availableness. If all corresponding technology factors of $T V D d, i$ and $T V R r, j$ comply with the comparative operators, an $R C r$ is capable of fulfilling the demand of a production order (see Fig. 4.). Subsequently, the supply of capacity for all capable $R C r$ is determined to update the configuration matrix. As a result, only capable and available $R C r$ are included in the following scheduling process.

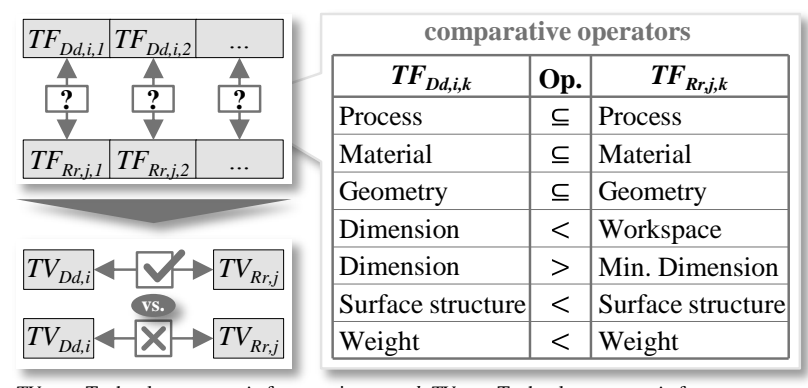

$T V_{D, j}=$ Technology vector $i$ of processing step $d ; T V_{R, j}=$ Technology vector $j$ of resource configuration $r ; T F_{D d, i, k}=$ Technology factor $k$ of $T V_{D d, i} ; T F_{R r, j, k}=$ Technology factor $k$ of $T V_{R r, j}$

Fig. 4. Demand-capability comparison.

Order allocation is executed by a modified NSGA-II. Following the evolutionary principle "survival of the fittest", the algorithm identifies near-optimal solutions for an optimization problem using the operator's selection, termination, recombination, mutation and substitution. The starting point is a randomly generated initial population of individuals, each representing a valid solution. A fitness function controls the optimization process. In the following, the developed approach is described in detail: Each individual is a combination of a variable number of genes consisting of alleles representing the order allocation (TVDd,i and $T V R r, j)$, category of capacity $(x i, t)$, job- 
split factor (JSdijl), branching points in the manufacturing process ( $a n d d, i)$ as well as scheduling priority (rank) (see Fig. 5).

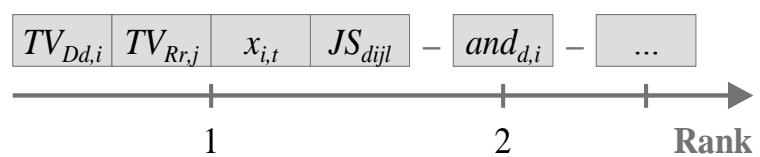

Fig. 5. Generic model of individuals.

The present optimization objective is minimal production costs, consisting of process, set up and transportation costs (see Fig. 6.). The majority of the costs can be integrated into the GA-operators through individual constraints requiring a repair function and a modified fitness function. The repair function ensures the complete representation of all production orders within an individual regarding the lot size of the processing steps and the manufacturing process. A decoding heuristic generates a valid order allocation, which dispatches every production order lot of an individual into a machine schedule according to the information given in each related gene, starting with the gene of highest scheduling priority. The fitness function subsequently evaluates the quality of the solution by calculating the sum of the objective and penalty functions. Adherence to delivery dates increases the calculated fitness value.

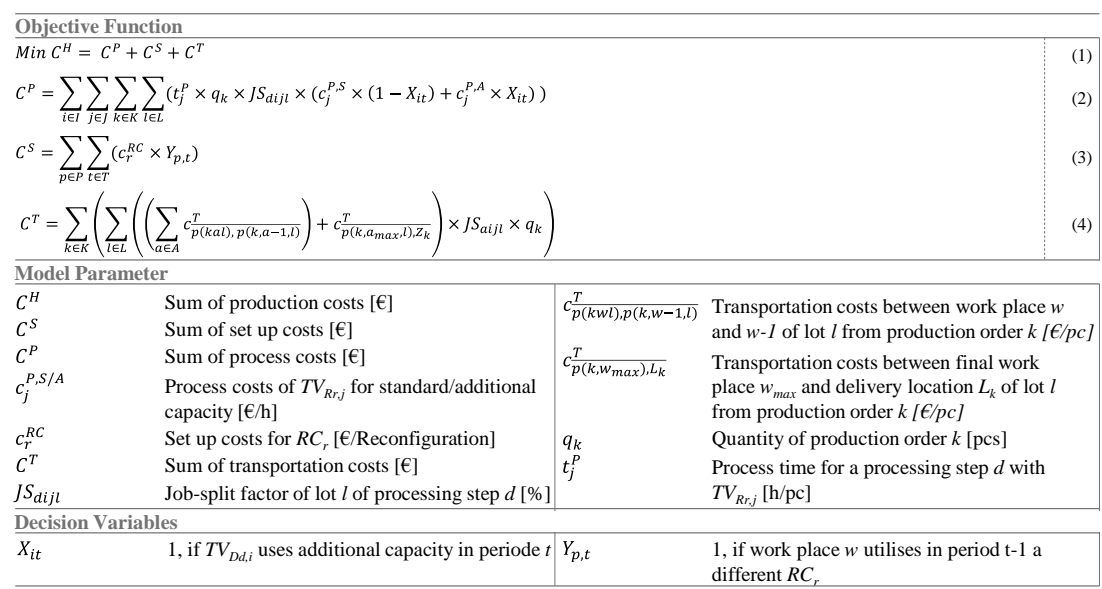

Fig. 6. Objective function of the optimization problem.

Initial population, substitution, termination and selection are implemented in line with the general principles of an NSGA-II. Two different mutation operators were selected: In mutation 1, some genes were randomly selected and mutated in $T V R r, j, x i, t$ or $J S d i j l$ to increase the diversity of individuals. In mutation 2, a pair of genes was randomly selected and swapped to modify the scheduling priority. 


\section{A prototypical application in the production of household appliances}

The developed approach was successfully applied in the replicated reconfigurable production network of a household appliance manufacturer, consisting of four factories and three target markets. The system for production planning was able to reduce the overall production costs, although improvements in runtime and detail level of costs are required.

\section{Conclusion}

The presented approach of reconfigurable production networks holds significant potential in order-based production. Especially issues concerning the utilization rate of various production sites by short and mid-term production planning show benefits. The genetic algorithm based on a configuration matrix and a demand-capacity comparison solves the problem of optimal order allocation.

To sum up, this paper showed a good opportunity to react fast to high market volatility in the order-based production by intelligent reconfiguration of an existing production network.

\section{References}

1.Abele, E., Reinhart, G.: Zukunft der Produktion. Herausforderungen, Forschungsfelder, Chancen. Hanser, München (2011).

2.Reinhart, G.: Industrie 4.0. Geschäftsmodelle, Prozesse, Technik. Hanser, München (2017).

3.Wiendahl, H-P.: Betriebsorganisation für Ingenieure. Hanser, München (2010).

4.Piller, F.; Tseng, M.M.: The customer centric enterprise; Advances in mass customization and personalization. Springer, Berlin (2003).

5.Atug, J.; Hees, A.; Wagner, M.; Braunreuther, S.; Reinhart, G.: Production Planning for Customer Innovated Products. Int. Conference IEEM, IEEE, New Jersey (2016).

6.Atug, J.; Braunreuther, S.; Reinhart, G.: Rekonfiguration von Produktionsnetzwerken. wt Werkstatttechnik online, 108, Springer, Düsseldorf (2018).

7.Koren, Y.; Heisel, U.; Jovane, F.; Moriwaki, T.; Pritschow, G.; Ulsoy, G.; van Brussel, H. Reconfigurable Manufacturing Systems. CIRP Annals, 48, (1999), S. 527-540.

8.Abele, E.; Meyer, T.; Näher, U.; Strube, G.; Sykes, R.: Global Production: A Handbook for Strategy and Implementation. Berlin, Heidelberg: Springer-Verlag (2008).

9.Wiendahl, H.-P.: Wandlungsfähigkeit. Schlüsselbegriff der zukunftsfähigen Fabrik. In: wtonline 92 (4), (2002), S. 122-127.

10.Hees, A.: System zur Produktionsplanung von rekonfugrierbaren Produktionssystemen. Utz Verlag, (2017).

11.Röhrs, A.: Produktionsmanagement in Produktionsnetzwerken. Lang, Frankfurt, (2003).

12.Westkämper, E; Zahn, E.: Wandlungsfähigeproduktionssysteme. Das Stuttgarter Unternehmensmodell. Springer, Berlin (2009).

13.Suginouchi, S.; Kokuryo, D.; Kaihara, T.: Value Co-creative Manufacturing System for Mass Customization. Procedia CIRP, 63, (2017).

14.Bensmaine, A.; Dahane, M.; Benyoucef, L.: A non-dominated sorting genetic algorithm based approach for optimal machines selection in reconfigurable manufacturing environment. Computers \& Industrial Engineering 66, (2013).

15.Deb, K., Pratap, A., Agarwal, S., Meyarivan, T.: A fast and elitist multiobjective genetic algorithm: NSGA-II. IEEE Transactions on Evolutionary Computation 6, (2002). 